J. Lake Sci.(湖泊科学), 2020, 32(4): 989-998

DOI 10. 18307/2020. 0408

(c) 2020 by Journal of Lake Sciences

\title{
基于水化学和氮氧同位素的贵州草海丰水期水体硝酸盐来源辨析”
}

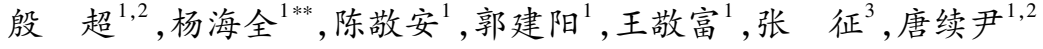 \\ (1:中国科学院地球化学研究所环境地球化学国家重点实验室,贵阳 550081) \\ (2: 中国科学院大学, 北京 100049) \\ (3: 西安科技大学测绘科学与技术学院,西安 710054)
}

\begin{abstract}
摘 要: 为明确草海湖水及其人湖河流硝酸盐污染的主要来源, 定量分析各来源的贡献率, 对草海湖水与人湖河流水化 学特征和水体硝酸盐的氮氧同位素组成进行了系统研究. 通过对草海湖水、河水、井水丰水期水体理化参数和同位素分 析发现: 湖水的 $\mathrm{NO}_{3}^{-} / \mathrm{Cl}^{-}$比值和 $\mathrm{Cl}^{-}$浓度表明其主要受牲畜粪便和城镇污水输人的影响, 而河水与井水则受农业活动和 城镇污水的共同影响. $\delta \mathrm{D}$-water 与 $\delta^{18} \mathrm{O}$-water 显示草海水体主要源于大气降水, 并有较强的蒸发作用. 湖水 $\delta^{15} \mathrm{~N}-\mathrm{NO}_{3}^{-}$和 $\delta^{18} \mathrm{O}-\mathrm{NO}_{3}^{-}$值分别为 $-5.56 \% \sim 11.30 \%$ 和 $0.02 \% 0 \sim 25.40 \%$, 较河水偏负而较井水偏正. 稳定同位素混合模型 (SIAR) 计算结 果表明草海湖水及其人湖河流硝酸盐主要源于化肥、土壤有机氮、牲畜粪便相关的农业活动, 其贡献率在 $50 \%$ 以上; 城镇 污水贡献率在 $22 \%$ 左右; 大气降水的贡献主要体现在湖水中.
\end{abstract}

关键词: 硝酸盐; 来源; 氮氧同位素; 贡献率;草海;丰水期

\section{Tracing nitrate sources with dual isotopes and hydrochemical characteristics during wet season in Lake Caohai, Guizhou Province*}

YIN Chao $^{1,2}$, YANG Haiquan ${ }^{1 * *}$, CHEN Jing'an ${ }^{1}$, GUO Jianyang ${ }^{1}$, WANG Jingfu ${ }^{1}$, ZHANG Zheng $^{3}$ \& TANG Xuyin ${ }^{1,2}$

(1: State Key Laboratory of Environmental Geochemistry, Institute of Geochemistry, Chinese Academy of Sciences, Guiyang 550081, P.R.China)

(2: University of Chinese Academy of Sciences, Beijing 100049, P.R.China)

(3: College of Geomatics, Xi'an University of Science and Technology, Xi'an 710054, P.R.China)

Abstract: The nitrogen and oxygen isotopic composition and hydrochemical characteristics of water were studied systematically to determine the main sources of nitrate in Lake Caohai and its rivers, and the contributions of each source were quantitatively analyzed. The ratio of $\mathrm{NO}_{3}^{-} / \mathrm{Cl}^{-}$to $\mathrm{Cl}^{-}$in the lake water showed that the lake was mainly affected by livestock manure and urban sewage in wet season, while the ratio in rivers and wells indicated that rivers were affected by agricultural activities and urban sewage. The analysis of $\delta \mathrm{D}$-water and $\delta^{18} \mathrm{O}$-water showed that atmospheric precipitation was the main source of water in Lake Caohai and its rivers, with a strong evaporation. The value of $\delta^{15} \mathrm{~N}_{-} \mathrm{NO}_{3}^{-}$and $\delta^{18} \mathrm{O}-\mathrm{NO}_{3}^{-}$in lake water were $-5.56 \% 0-11.30 \% 0$ and $0.02 \% 0-$ $25.40 \%$ respectively, which were more negative than the rivers and more positive than the wells. The results of SIAR model showed that nitrate in Lake Caohai and its rivers mainly came from agricultural activities related to fertilizer, soil organic $\mathrm{N}$ and livestock manure, and its contributions was more than $60 \%$. The contribution rate of urban sewage was about $25 \%$. The contribution of atmospheric precipitation was mainly reflected in the lake water.

Keywords: Nitrate; sources; $\delta^{15} \mathrm{~N}^{-\mathrm{NO}_{3}^{-}}$and $\delta^{18} \mathrm{O}-\mathrm{NO}_{3}^{-}$; contributions; Lake Caohai; wet season

* 2019-11-17 收稿; 2019-12-12 收修改稿.

贵州省重大科技专项项目（黔科合重大专项字 [2016] 3022 号）、国家自然科学基金项目( U1612441,41807394)和 贵州省科学技术基金项目（黔科合基础[2018]1174)联合资助.

** 通信作者; E-mail: yanghaiquan@ vip.skleg.cn. 
随着人类社会经济发展和生产生活活动的不断增加, 全球工农业和城市生活污水排放量持续上升 ${ }^{[1]}$, 对全球生态系统的氮生物地球化学循环产生了深远影响 ${ }^{[2]}$. 氮元素可以多种形式存在, 硝酸盐是最主要的 形式; 而硝酸盐污染可引发水体富营养化和水质退化等水环境问题 ${ }^{[3]}$, 对许多河流、水库、湖泊和地下水资 源形成了严重威胁 ${ }^{[4]}$, 是目前全球水生生态系统面临的主要环境问题之一. 因此硝酸盐污染防控和来源辨 识,对水安全的保障和硝酸盐污染的管理至关重要. 水体硝酸盐来源十分广泛,潜在的主要来源包括大气降 水 ${ }^{[3]}$ 、城市生活污水和工业废水、土壤有机 $\mathrm{N}$ 和农业肥料等 ${ }^{[5-6]}$. 硝酸盐的来源不同,其氮氧同位素组成范围 也往往不同 ${ }^{[7-8]}$. 土壤有机 $\mathrm{N}$ 的 $\delta^{15} \mathrm{~N}$ 和 $\delta^{18} \mathrm{O}$ 范围分别为 $2 \% 0 \sim 9 \%$ 和 $-10 \% 0 \sim 10 \%{ }^{[7]}$, 牲畜粪便和城市污水 $\delta^{15} \mathrm{~N}$ 和 $\delta^{18} \mathrm{O}$ 范围分别为 4\%o 25\%o和-5\%o 10\% , 大气降水 $\delta^{15} \mathrm{~N}$ 和 $\delta^{18} \mathrm{O}$ 范围分别为 $-13 \% 0 \sim 13 \% 0$ 和 $25 \%$ $75 \%$, 工业合成氮肥 $\delta^{15} \mathrm{~N}$ 和 $\delta^{18} \mathrm{O}$ 范围分别为 $-5 \% 0 \sim 5 \%$ 和 17\% $~ 25 \%{ }^{[9-10]}$. 随着同位素分析技术的发展, 国 内外对于硝酸盐来源识别的研究成果不断丰富 ${ }^{[11-13]}$. Elisante 等认为㴮公河地下水中 $\mathrm{NO}_{3}^{-}$主要来源于人类 活动特别是畜牧业 ${ }^{[14]}$. 在美国德克萨斯中部的研究表明, 含水层硝酸盐可能主要源于有机 $N$ 的水下硝化作 用 ${ }^{[15]}$. 同时不少学者利用稳定同位素混合模型 (SIAR), 定量分析各硝酸盐来源的贡献率. Soto 利用 SIAR 分 析了 Assiniboine River 硝酸盐的来源, 结果显示城镇污水和市政废物的贡献率可高达 $62 \%$, 而红河中的硝酸 盐 $40 \%$ 主要来源于农业肥料 ${ }^{[16]}$. 国内的相关研究发现农业和工业活动是太湖中硝酸盐的主要来源, 其贡献 率分别为 $50.8 \%$ 和 $33.9 \%{ }^{[17]}$. 在江淮丘陵区,城市污水、牲畜粪便及土壤有机 $\mathrm{N}$ 被认为是主要来源, 贡献率 分别为 $28 \% \sim 36 \%$ 和 $24 \% \sim 27 \%{ }^{[18]}$.

随着草海流域人口增加和城镇化的快速发展, 草海水污染程度急剧上升, 水质持续快速恶化, 氮污染风 险不断增加 ${ }^{[19-20]}$. 因此对草海湖水和河水硝酸盐来源进行同位素示踪分析和各污染源贡献率的定量计算, 对实现草海氮污染的管控, 提升草海污染治理成效至关重要. 本文通过分析草海湖水、河水、地下水、降水的 硝酸盐氮氧同位素组成, 研究草海水体硝酸盐的 $\delta^{15} \mathrm{~N}-\mathrm{NO}_{3}^{-}$与 $\delta^{18} \mathrm{O}-\mathrm{NO}_{3}^{-}$同位素组成和 $\delta \mathrm{D}$-water 与 $\delta^{18} \mathrm{O}$-water 同位素组成分布特征; 并结合贝叶斯 SIAR 模型定量辨识草海硝酸盐污染主要来源. 从而为草海有针对性 的、快速有效的氮污染防治提供科学的数据和理论支撑.

\section{1 材料与方法}

\section{1 研究区概况}

贵州草海 $\left(26^{\circ} 47^{\prime} \sim 26^{\circ} 52^{\prime} \mathrm{N}, 104^{\circ} 10^{\prime} \sim 104^{\circ} 20^{\prime} \mathrm{E}\right)$ 位于贵州省西北边缘威宁彝族回族苗族自治县县城西 南部, 海拔 $2172 \sim 2234 \mathrm{~m}$, 区内以碳酸盐岩分布为主, 漏斗、落水洞和溶蚀洼地盆地等岩溶地貌广泛发育. 草 海位于威宁一水城大背斜向北弯曲的顶部, 在构造阻断作用下, 河流汇集形成的构造湖, 是一个典型的高原 岩溶淡水湖, 也是贵州省最大的天然淡水湖泊 ${ }^{[21-22]}$. 草海湖泊正常蓄水面积 $19.8 \mathrm{~km}^{2}$, 正常水位 $2171.7 \mathrm{~m}$, 最大宽度 $6.2 \mathrm{~km}$, 最大水深 $5.0 \mathrm{~m}$, 平均水深 $1.5 \mathrm{~m}^{[23]}$. 草海流域为亚热带季风气候, 垂直气候带明显, 年均气 温 $10.6^{\circ} \mathrm{C}$; 年均降水量 $950.9 \mathrm{~mm}$, 其中 $88 \%$ 集中在 5-10 月; 受降水的季节变化影响, 草海丰水期水位可达 $2172.0 \mathrm{~m}$, 枯水期为 $2171.2 \mathrm{~m}$; 湖水主要由降水和地下水补给, 呈弱碱性, 高硬度 ${ }^{[22,24]}$. 近年来由于工农业活 动和城镇快速发展, 威宁县城污水及周边居民生活垃圾的无序排放, 及草海湖周边农业活动化肥和农药使 用量日趋增加影响, 草海水生生态环境受到严重破坏 ${ }^{[25]}$.

\section{2 样品采集与分析}

1.2.1 样品采集与测试方法 2019 年 7 月 (丰水期) 在草海和 6 条主要河水流中分别设置 28 个湖水样点 $(\mathrm{S} 1 \sim \mathrm{S} 28)$ 和 6 个河水点 $(\mathrm{R} 1 \sim \mathrm{R} 6)$, 并对草海周边区域 3 个井水点 $(\mathrm{W} 1 \sim \mathrm{W} 3)$ 和雨水点 $(\mathrm{P} 1 \sim \mathrm{P} 3)$ 进行了样 品采集 (图 1). 同时采集草海湖泊周边的土壤、化肥和牲畜粪便样品. 水体温度 ( T)、溶解氧 ( DO)、电导率 (EC) 和 $\mathrm{pH}$ 用 YSI-6610 pro 多参数水质分析仪现场测定. 水样装人预先洗净的聚乙烯瓶中, 土壤、化肥和牲 畜粪便样品置人样品袋中, 所有样品采集后均立即冷藏保存, 并尽快送至实验室进行前处理和分析测试.

水体阴阳离子浓度和氢氧同位素组成测试在中国科学院地球化学研究所环境地球化学国家重点实验 室完成. 阴离子由离子色谱仪 (ICS90 型) 测定, 阳离子用电感耦合等离子体发射光谱仪 (VISA-MPX 型) 测 定, 最低检出限均为 $0.01 \mathrm{mg} / \mathrm{L}$. 水体氨氮 $\left(\mathrm{NH}_{3}-\mathrm{N}\right)$ 浓度采用纳氏试剂分光光度法测定 ( HJ 535-2009). 水 体 $\delta \mathrm{D}$-water 与 $\delta^{18} \mathrm{O}$-water 同位素组成由气体同位素比值质谱仪 (MAT253) 测定, 分析精度分别为 $\pm 0.5 \% 0$ 和 


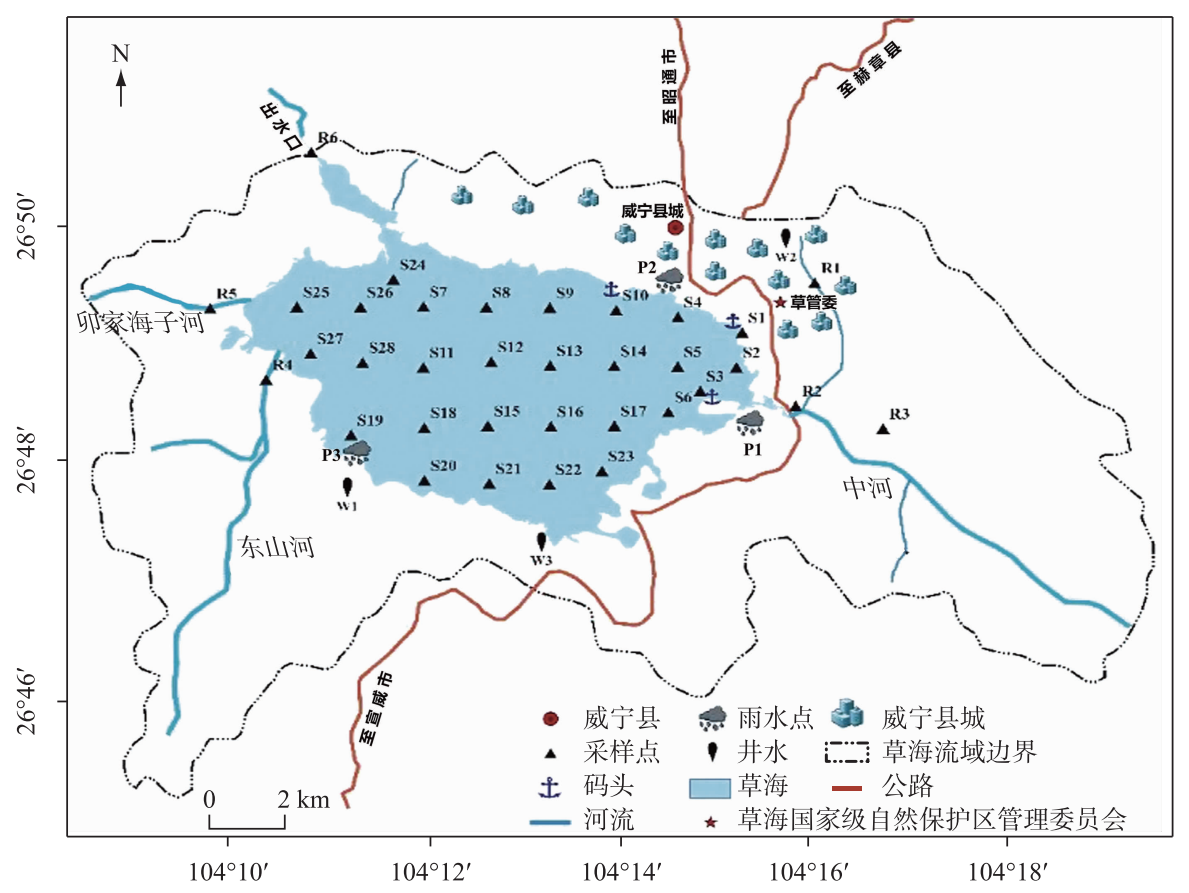

图 1 草海采样点分布

Fig.1 Distribution of the sampling sites in Lake Caohai

$\pm 0.2 \%$, 测定结果以 V-SMOW 标准表示. 水体、土壤、化肥和牲畜粪便的硝酸盐氮氧同位素组成由中国农业 科学院农业环境稳定同位素实验室 (AESIL, CAAS), 经细菌反硝化法前处理后, 通过 Delta V-Precon 进行测 定, 精度为 $\pm 0.4 \%$, 测定结果分别以大气 $\mathrm{N}_{2}\left(\delta^{15} \mathrm{~N}\right)$ 和 V-SMOW $\left(\delta^{18} \mathrm{O}\right)$ 标准表示.

1.2 .2 稳定同位素混合模型 采用稳定同位素混合模型 (SIAR) 对各硝酸盐污染源贡献率进行计算, SIAR 模 型表达式如下 ${ }^{[26]}$ :

$$
\begin{aligned}
X_{i j}= & \sum_{k=1}^{k} p_{k}\left(S_{j k}+C_{j k}\right)+\varepsilon_{i j} \\
S_{j k} & \sim N\left(\mu_{j k}, \omega_{j k}^{2}\right) \\
C_{j k} & \sim N\left(\lambda_{j k}, \tau_{j k}^{2}\right) \\
\varepsilon_{i j} & \sim N\left(0, \sigma_{j}^{2}\right)
\end{aligned}
$$

式中, $X_{i j}$ 表示第 $i$ 个样品中第 $j$ 种同位素值 $(i=1,2,3, \cdots, N ; j=1,2,3, \cdots, J) ; S_{j k}$ 是第 $k$ 种源中第 $j$ 种同位素 的值 $(k=1,2,3, \cdots, K), \mu_{j k}$ 表示平均值, $\omega_{j k}^{2}$ 为正态分布的方差; $C_{j k}$ 是第 $j$ 种同位素在第 $k$ 个源上的分馏系数， $\lambda_{j k}$ 为平均值, $\tau_{j k}^{2}$ 为正态分布的方差; $p_{k}$ 为第 $k$ 个源的贡献率, 由模型计算得到; $\varepsilon_{i j}$ 为残差, 表示各混合物间剩 下的未量化的变异,平均值为 $0, \sigma_{j}^{2}$ 为正态分布的方差.

\section{2 结果与讨论}

\section{1 草海水质特征}

草海丰水期湖水水温在 $20.0 \sim 22.5^{\circ} \mathrm{C}$ 之间, 各点差异不大; 河水和井水则相对较低, 范围分别为 15.6 22.0 和 $14.5 \sim 16.7^{\circ} \mathrm{C}$ (表 1 ). 湖水 DO 浓度总体上高于 $10 \mathrm{mg} / \mathrm{L}(8.12 \sim 17.7 \mathrm{mg} / \mathrm{L})$, 河水和井水的 DO 浓度分别 为 $5.06 \sim 5.79$ 和 $1.42 \sim 4.50 \mathrm{mg} / \mathrm{L}$. 丰水期湖水 $\mathrm{EC}$ 在 $0.185 \sim 0.504 \mathrm{mS} / \mathrm{cm}$, 较河水 $(0.204 \sim 0.600 \mathrm{mS} / \mathrm{cm})$ 和井水 ( 0.339 1.22 mS/cm) 明显偏低; 其中 R4、R5、R6 和 W3 受降水影响, 流量大幅增加, 故 EC 较其他河流和井水点 
偏低. 湖水 $\mathrm{pH}$ 值较高, 范围为 8.12 10.31; 而河水与井水则略微偏低, 其值在 7.85 8.74 之间 (图 2).

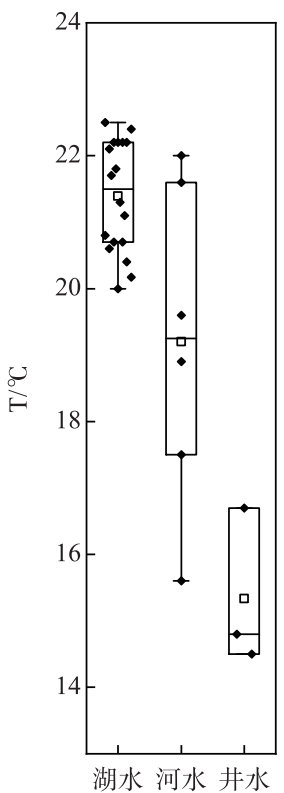

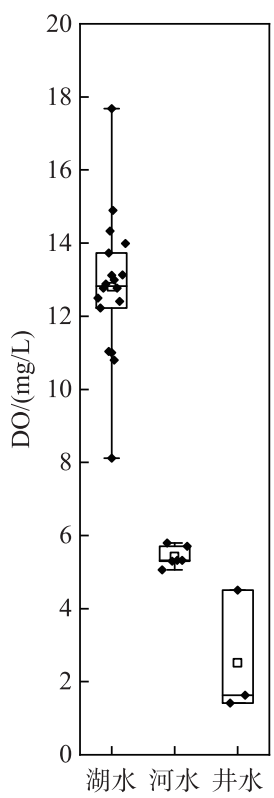
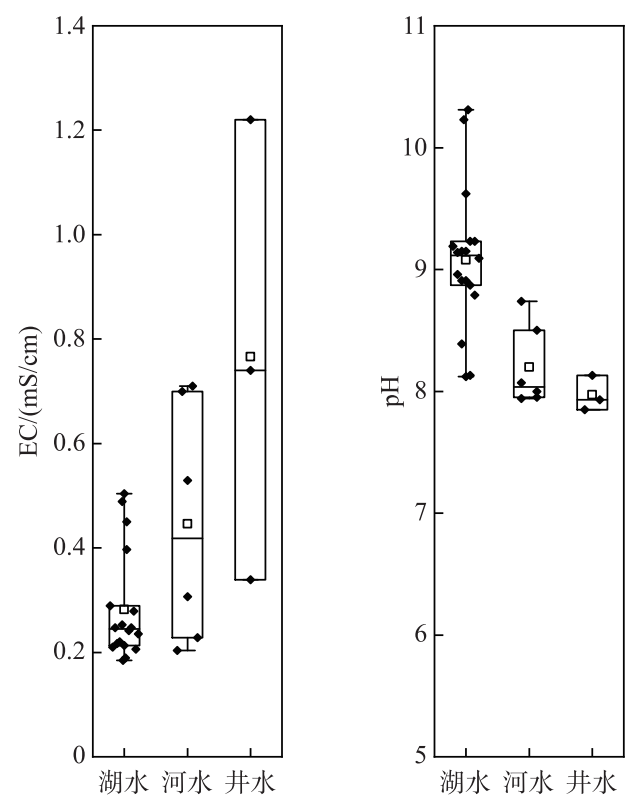

图 2 草海采样点水质参数

Fig. 2 Water quality parameters of sampling sites in Lake Caohai

\section{2 草海水体水化学特征}

2.2.1 草海水体离子浓度 草海丰水期湖水阴离子丰水期浓度呈现出 $\mathrm{HCO}_{3}^{-}>\mathrm{SO}_{4}^{2-}>\mathrm{Cl}^{-}>\mathrm{NO}_{3}^{-}$的变化规律. 除 S27 外, 草海湖水 $\mathrm{NO}_{3}^{-}$浓度在 $0.29 \sim 4.50 \mu \mathrm{mol} / \mathrm{L}$, 显著低于河水的 $6.60 \sim 507 \mu \mathrm{mol} / \mathrm{L}$; 井水 $\mathrm{NO}_{3}^{-}$浓度也相 对较高, 浓度可达 114 632 $\mu \mathrm{mol} / \mathrm{L}$ (表 1). 湖水 $\mathrm{S} 27$ 的 $\mathrm{NO}_{3}^{-}$浓度显著高于其他湖水点, 其原因是 $\mathrm{S} 27$ 点位于 东山河人湖口, 受到河流与陆地的影响很大, 故其 $\mathrm{NO}_{3}^{-}$浓度达 $166 \mu \mathrm{mol} / \mathrm{L}$. 而河水 $\mathrm{R} 6$ 的 $\mathrm{NO}_{3}^{-}$浓度低于其他

表 1 草海水体水化学特征

Tab.1 Hydrochemical characteristics of waters in Lake Caohai

\begin{tabular}{ccccc}
\hline 理化因子 & 湖水 & 河水 & 井水 & 雨水 \\
\hline $\mathrm{T} /{ }^{\circ} \mathrm{C}$ & $9.10 \pm 0.60$ & $8.20 \pm 0.30$ & $8.00 \pm 0.10$ & - \\
$\mathrm{pH}$ & $9.09 \pm 0.58$ & $8.20 \pm 0.31$ & $7.97 \pm 0.12$ & - \\
$\mathrm{DO} /(\mathrm{mg} / \mathrm{L})$ & $12.8 \pm 1.97$ & $5.42 \pm 0.25$ & $2.52 \pm 1.41$ & - \\
$\mathrm{EC} /(\mathrm{mS} / \mathrm{cm})$ & $0.29 \pm 0.10$ & $0.45 \pm 0.21$ & $0.77 \pm 0.36$ & $0.01 \pm 0$ \\
$\mathrm{NO}_{3}^{-} /(\mathrm{mmol} / \mathrm{L})$ & $0.01 \pm 0.04$ & $0.29 \pm 0.19$ & $0.40 \pm 0.22$ & - \\
$\mathrm{NH}_{3}-\mathrm{N} /(\mu \mathrm{mol} / \mathrm{L})$ & $1.75 \pm 0.03$ & $1.82 \pm 0.17$ & $1.69 \pm 0.04$ & $0.01 \pm 0$ \\
$\mathrm{HCO}_{3}^{-} /(\mathrm{mmol} / \mathrm{L})$ & $1.15 \pm 0.34$ & $2.27 \pm 1.23$ & $3.25 \pm 0.65$ & $0.02 \pm 0.01$ \\
$\mathrm{Cl}^{-} /(\mathrm{mmol} / \mathrm{L})$ & $0.50 \pm 0.14$ & $0.33 \pm 0.09$ & $0.25 \pm 0.08$ & $0.01 \pm 0$ \\
$\mathrm{SO}_{4}^{2-} /(\mathrm{mmol} / \mathrm{L})$ & $0.56 \pm 0.34$ & $0.95 \pm 0.66$ & $1.76 \pm 1.33$ & $0.04 \pm 0.02$ \\
$\mathrm{~K}^{+} /(\mathrm{mmol} / \mathrm{L})$ & $0.09 \pm 0.02$ & $0.12 \pm 0.03$ & $0.04 \pm 0.02$ & $0.01 \pm 0$ \\
$\mathrm{Ca}^{2+} /(\mathrm{mmol} / \mathrm{L})$ & $1.31 \pm 0.51$ & $0.62 \pm 0.36$ & $2.46 \pm 1.92$ & $0.01 \pm 0$ \\
$\mathrm{Na}^{+} /(\mathrm{mmol} / \mathrm{L})$ & $0.25 \pm 0.13$ & $0.45 \pm 0.10$ & $0.21 \pm 0.10$ & $0.51 \pm 0.29$ \\
$\mathrm{Mg}^{2+} /(\mathrm{mmol} / \mathrm{L})$ & $0.40 \pm 0.18$ & $0.43 \pm 0.09$ & & \\
\hline
\end{tabular}

一表示未检测. 
河水点的主要原因是其为湖水的出水口, 主要受湖水的影响, 因此 $\mathrm{NO}_{3}^{-}$浓度偏低, 且水体各参数与湖水较为 接近. 湖水氨氮浓度范围在 $1.72 \sim 1.78 \mu \mathrm{mol} / \mathrm{L}$, 河水与井水氨氮浓度范围分别为 $1.65 \sim 1.99$ 和 $1.65 \sim 1.73$ $\mu \mathrm{mol} / \mathrm{L}$; 各类水体氨氮浓度差异并不明显.

丰水期湖水 $\mathrm{Cl}^{-}$浓度在 $0.28 \sim 0.95 \mathrm{mmol} / \mathrm{L}$, 总体上高于河水与井水; 降水的 $\mathrm{Cl}^{-}$浓度最高仅 $0.01 \mathrm{mmol} / \mathrm{L}$. 水体中 $\mathrm{HCO}_{3}^{-}$浓度在阴离子中比重最大, 湖水、河水和井水分别可达 $0.75 \sim 2.60 、 1.10 \sim 4.60$ 和 $2.60 \sim 3.90$ $\mathrm{mmol} / \mathrm{L}$. 草海湖水 $\mathrm{SO}_{4}^{2-}$ 浓度除 $\mathrm{S} 1 \sim \mathrm{S} 4$ 较高外 $\left(>0.9 \mathrm{mmol} / \mathrm{L}\right.$ ), 其他湖水点 $\mathrm{SO}_{4}^{2-}$ 浓度在 $0.25 \sim 0.79 \mathrm{mmol} / \mathrm{L}$ 之 间. 河水 $\mathrm{SO}_{4}^{2-}$ 浓度在不同点差异较大, $\mathrm{R} 1 \sim \mathrm{R} 3$ 的 $\mathrm{SO}_{4}^{2-}$ 浓度最低为 $1.16 \mathrm{mmol} / \mathrm{L}$, 而 $\mathrm{R} 4 \sim \mathrm{R} 6$ 的 $\mathrm{SO}_{4}^{2-}$ 浓度最高 为 $0.36 \mathrm{mmol} / \mathrm{L}$. 井水 $\mathrm{SO}_{4}^{2-}$ 浓度在 $0.23 \sim 3.48 \mathrm{mmol} / \mathrm{L}$ 之间, 降水 $\mathrm{SO}_{4}^{2-}$ 浓度最高为 $0.02 \mathrm{mmol} / \mathrm{L}$. 除雨水外, 草 海各类水体的 $\mathrm{K}^{+} 、 \mathrm{Ca}^{2+} 、 \mathrm{Na}^{+} 、 \mathrm{Mg}^{2+}$ 浓度分别在 $0.02 \sim 0.17 、 0.31 \sim 1.88 、 0.07 \sim 0.59$ 和 $0.13 \sim 0.69 \mathrm{mmol} / \mathrm{L}$ 之间. 2.2.2 水体 $\mathrm{NO}_{3}^{-}$与 $\mathrm{Cl}^{-}$分布关系 丰水期草海湖水 $\mathrm{NO}_{3}^{-}$和 $\mathrm{Cl}^{-}$的分布关系表现出 $\mathrm{Cl}^{-}$高, $\mathrm{NO}_{3}^{-}$低的特征; 井水与河水的 $\mathrm{Cl}^{-}$浓度波动范围不大, 但各点 $\mathrm{NO}_{3}^{-}$浓度的差异十分明显. 大气降水的 $\mathrm{NO}_{3}^{-}$和 $\mathrm{Cl}^{-}$主要来自于周边大气环境, 其浓度 很低; 而无论湖水、河水还是井水, 两种离子的浓度均与大 气降水的分布距离较远, 表明丰水期大气降水并不是影响 草海水体 $\mathrm{Cl}^{-}$和 $\mathrm{NO}_{3}^{-}$浓度的直接或主要因素 (图 3). 由于 $\mathrm{Cl}^{-}$的保守化学行为, $\mathrm{NO}_{3}^{-} / \mathrm{Cl}^{-}$比值可作为流域内硝态氮分 布的混合或生物过程的指示剂 ${ }^{[27-28]}$. 通常化肥具有较高的 $\mathrm{NO}_{3}^{-}$浓度和 $\mathrm{NO}_{3}^{-} / \mathrm{Cl}^{-}$比值; 而城镇生活污水 $\mathrm{Cl}^{-}$浓度很高, $\mathrm{NO}_{3}^{-} / \mathrm{Cl}^{-}$比值则较低 ${ }^{[2]}$. 从草海水体 $\mathrm{Cl}^{-}$与 $\mathrm{NO}_{3}^{-} / \mathrm{Cl}^{-}$的关系 可知, 大部分湖水点 $\mathrm{NO}_{3}^{-} / \mathrm{Cl}^{-}$比值低而 $\mathrm{Cl}^{-}$偏高, 这与牲畜 粪便和城市生活污水端元特征相似; 说明在丰水期, 湖水 主要受上述两个因素影响. 部分河流和井水表现出较高 $\mathrm{NO}_{3}^{-} / \mathrm{Cl}^{-}$比值和偏低 $\mathrm{Cl}^{-}$值的分布状况, 表明其主要受到农

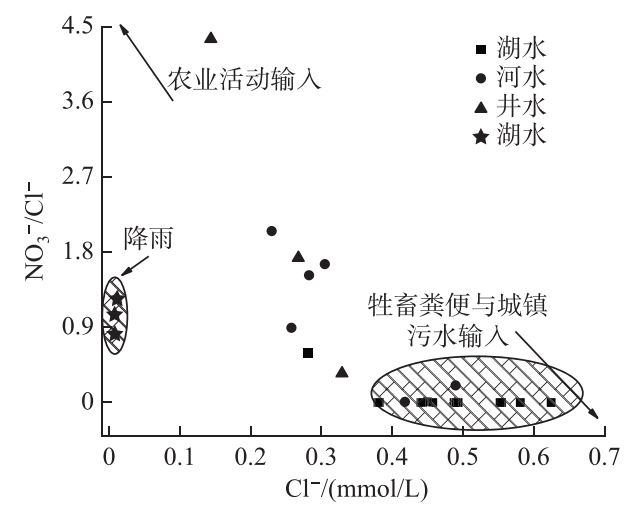

图 3 草海水体 $\mathrm{NO}_{3}^{-} / \mathrm{Cl}^{-}$比值与 $\mathrm{Cl}^{-}$浓度的关系

Fig.3 The relationship between $\mathrm{NO}_{3}^{-} / \mathrm{Cl}^{-}$ and $\mathrm{Cl}^{-}$concentration of water in Lake Caohai 业和城镇污水的共同影响.

\section{3 草海水体氢氧同位素组成}

丰水期草海湖水 $\delta D$-water 值与 $\delta^{18} \mathrm{O}$-water 值变化范围较大, 分别为 $-66.06 \% 0 \sim-22.0 \% 0$ 和 $-9.09 \%$ $-1.62 \% 0$; 河水 $\delta \mathrm{D}$-water 值与 $\delta^{18} \mathrm{O}$-water 值范围分别为 $-73.12 \% 0 \sim-31.18 \%$ 和 $-10.23 \% 0 \sim-3.55 \% 0$; 井水则分 别为 $-73.31 \% 0 \sim-72.25 \%$ 和 $-10.65 \%$ - 10.01\% (表 2). 其中湖水 S1 S6 和 S23、S27 水样氢氧同位素组成 较其他湖水点更为偏负, 表明这些采样点湖水受蒸发作用影响小 ${ }^{[30]}$; 河流 R6 水体氢氧同位素组成与其他 和河水采样点相比显著偏正, 其原因在于 R6 为出水口, 受湖水影响十分显著, 因此其同位素组成与湖水接 近. 综上所述, 湖水较河水和地下水相比,受蒸发作用影响较强.

表 2 草海水体氢氧同位素和硝酸盐氮氧同位素组成

Tab.2 Hydrogen, oxygen isotopes of water and nitrogen, oxygen isotopes of nitrate of water in Lake Caohai

\begin{tabular}{|c|c|c|c|c|}
\hline & 湖水 & 河水 & 井水 & 雨水 \\
\hline$\delta \mathrm{D}$-water & $-56.6 \% \pm \pm 16.99 \%$ & $-52.9 \% \pm 21.7 \%$ & $-39.5 \% \pm 24.2 \%$ & $-56.5 \% \pm 5.89 \%$ \\
\hline$\delta^{18} \mathrm{O}$-water & $-7.64 \% \pm \pm 2.90 \%$ & $-7.07 \%$ $\pm 3.52 \%$ & $-4.89 \%$ 0 $\pm 3.87 \%$ & $-7.56 \%$ o $\pm 1.10 \%$ \\
\hline$\delta^{15} \mathrm{~N}-\mathrm{NO}_{3}^{-}$ & $7.64 \% \pm \pm 4.60 \%$ & $0.860 \% \pm 4.85 \%$ & $10.2 \%$ $\% 5.64 \%$ & $-9.59 \%$ $\pm 5.83 \%$ \\
\hline$\delta^{18} \mathrm{O}-\mathrm{NO}_{3}^{-}$ & $2.93 \% 0 \pm 2.51 \%$ & $15.7 \% \pm \pm 6.40 \%$ & $1.97 \% \pm \pm 2.42 \%$ & $49.0 \% \pm 5.02 \%$ \\
\hline
\end{tabular}

前期研究表明,降水 $\delta \mathrm{D}$-water 值与 $\delta^{18} \mathrm{O}$-water 值可示踪大气降水水汽来源,两者间的相关关系被称为大 气降水线 ${ }^{[31]}$. 大气降水线通常随水汽的来源、输送方式、季节变化、降水期间当地环境等条件的变化而不 同 $^{[32-33]}$; 故不同地区的大气降水线具有一定的差异. 由图 4 可知,草海各监测点水体氢氧同位素组成均较接 
近全球大气降水线 (GMWL), 表明草海水体主要源于大气降水. 草海地区大气降水线方程 (LMWL) 通过 GNIP 中最近的贵阳监测站数据计算而来,得出草海流域 LMWL 为: $y=8.8216 x+22.065$. 丰水期草海水体 $\delta \mathrm{D}$-water 值与 $\delta^{18} \mathrm{O}$-water 值间呈现出十分显著的相关性, $R^{2}$ 可达 0.994. 无论湖水、河流还是井水的 $\delta \mathrm{D}$-water 值与 $\delta^{18} \mathrm{O}$-water 值均在 LMWL 线下方, 表明草海水体受到一定的蒸发作用影响.

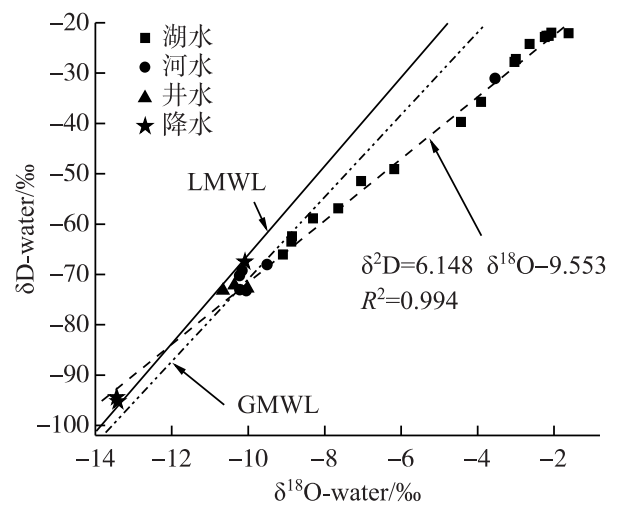

图 4 草海水体 $\delta \mathrm{D}$-water 与 $\delta^{18} \mathrm{O}$-water 分布

Fig.4 Distribution of $\delta \mathrm{D}$-water and $\delta^{18} \mathrm{O}$-water of water in Lake Caohai

\section{4 草海硝酸盐来源示踪}

2.4 .1 草海水体氮氧同位素组成 丰水期草海湖水、河水和井水 $\delta^{15} \mathrm{~N}^{-\mathrm{NO}_{3}^{-}}$值均波动较大, 分别达 $-5.56 \% 0 \sim$ $11.3 \%$ 、 $1.40 \% 0 \sim 15.1 \%$ 和 3.41\%o 17.2\%o, 雨水 $\delta^{15} \mathrm{~N}-\mathrm{NO}_{3}^{-}$值则在 $-17.0 \%$ $-2.73 \% 0$ 之间; 可见河水和井水

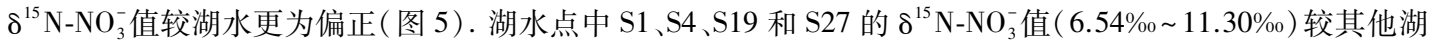
水偏正, 其原因可能在于距岸边居民区和河口较近, 受城市污水和河流的影响较大所致. 在 $\delta^{18} \mathrm{O}-\mathrm{NO}_{3}^{-}$值方 面,除雨水 $(45.1 \% 0 \sim 56.1 \%$ ) 最为偏正外, 湖水 $(0.02 \% 0 \sim 25.40 \%$ ) 较河水与井水总体上偏正; 而河水与井水 的差异却非常小, 分别为 $-0.876 \%$ 7. $13 \% 0$ 和 $0.150 \% 0 \sim 5.40 \%$. 此外, 草海周边土壤 $\delta^{15} \mathrm{~N}^{-\mathrm{NO}_{3}^{-}}$值和 $\delta^{18} \mathrm{O}-\mathrm{NO}_{3}^{-}$ 值分别为 $1.78 \% 0 \sim 32.9 \%$ 和 $1.62 \% 0 \sim 15.6 \%$; 化肥 $\delta^{15} \mathrm{~N}-\mathrm{NO}_{3}^{-}$值和 $\delta^{18} \mathrm{O}-\mathrm{NO}_{3}^{-}$值分别为 $-25.3 \% 0 \sim 53.5 \% 0$ 和 $1.46 \% 0 \sim$ $23.8 \% 0$; 城镇污水和牲畜粪便的 $\delta^{15} \mathrm{~N}^{-\mathrm{NO}_{3}^{-}}$值分别为 $4.83 \% 0 \sim 8.60 \% 0$ 和 $3.01 \% 0 \sim 11.12 \% 0, \delta^{18} \mathrm{O}-\mathrm{NO}_{3}^{-}$值则分别达 $-0.876 \%$ 5.32\%o和 $9.37 \%$ 31.2\%

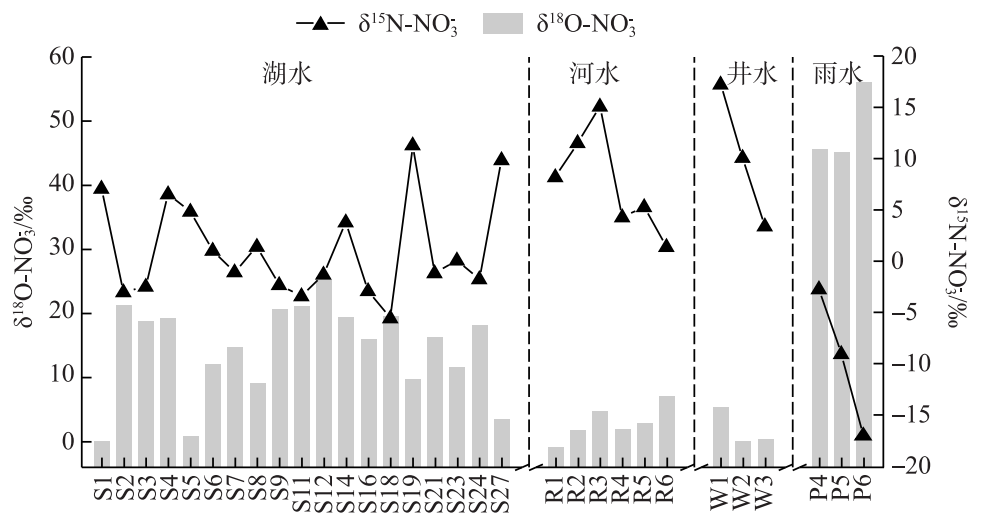

图 5 草海水体 $\delta^{15} \mathrm{~N}-\mathrm{NO}_{3}^{-}$和 $\delta^{18} \mathrm{O}-\mathrm{NO}_{3}^{-}$分布

Fig.5 Distribution of $\delta^{15} \mathrm{~N}-\mathrm{NO}_{3}^{-}$and $\delta^{18} \mathrm{O}-\mathrm{NO}_{3}^{-}$of water in Lake Caohai

2.4 .2 草海水体硝酸盐主要来源分析 草海丰水期湖水 $\delta^{15} \mathrm{~N}-\mathrm{NO}_{3}^{-}$与 $\delta^{18} \mathrm{O}-\mathrm{NO}_{3}^{-}$主要分布在无机化肥端元区 
(图 6), 这表明雨季草海硝酸盐主要来源于农业生产 (施肥) 活动; 同时部分湖水点落在混合端元区和城市 污水与牲畜粪便端元区, 说明湖水也受到一定的城市污水和牲畜粪便的影响. 河水与井水则主要分布在城 镇污水和牲畜粪便端元区, 表明河水和井水主要受这两个端元的影响. 此外, 河水与井水受降水的影响流量 增加, 加之其距离人口密集区较近, 城镇污水顺势进人河道和地下水, 故其污染物质主要源于城镇污水和牲 畜排泄物. 这同时说明草海地区的污染物质来源, 可能会受气候和水文条件 (降水、蒸发等) 变化的影响. 如 前文所述, S1、S4 和 S27 因其离岸较近的影响, 位于城镇污水与牲畜粪便端元区和无机化肥端元区; S19 因 处于流量较大的东山河河口附近, 故 S19 同位素分布区与河流相近. 此外, R6 因主要来源于湖水, 因此其同 位素特征偏向湖水点分布区.

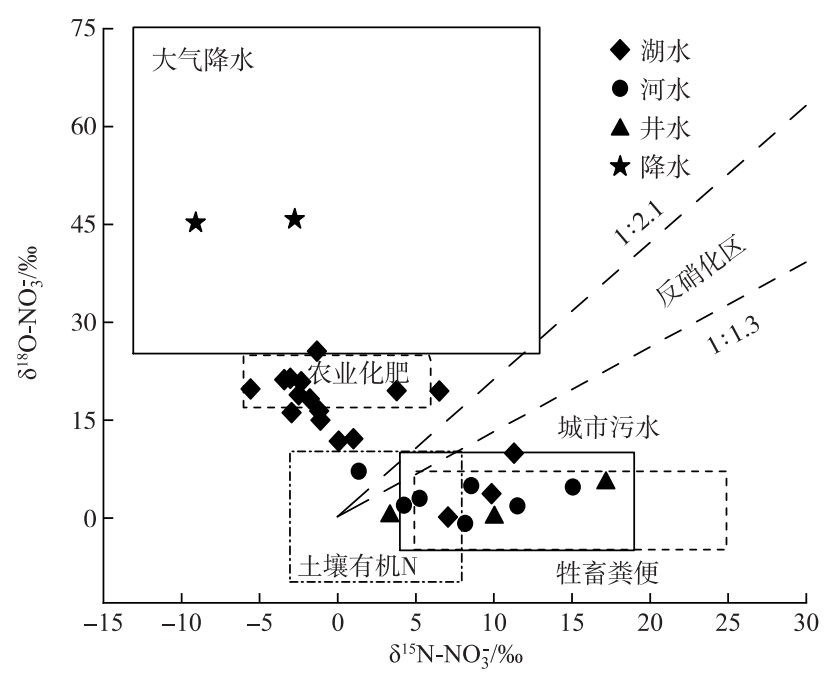

图 6 草海水体硝酸盐来源分布

Fig.6 Distribution of nitrate sources of water in Lake Caohai

硝酸盐氮氧同位素组成特征除受到其来源的影响,氮在迁移过程中发生的一系列生物化学作用如硝化 作用、反硝化作用、固氮作用、扩散作用和挥发作用等都会引起氮同位素分馏, 从而影响硝酸盐氮氧同位素 组成. 矿化作用和固氮作用通常具有较小的同位素分馏 ${ }^{[34]}$; 同时受草海水体 $\mathrm{NH}_{3}-\mathrm{N}$ 浓度偏低的影响, 水体 不会发生氨气挥发现象.

在硝化作用过程中, 微生物可将水体中 $\mathrm{NH}_{4}^{+}$转化为 $\mathrm{NO}_{2}^{-}$, 再将 $\mathrm{NO}_{2}^{-}$转化为 $\mathrm{NO}_{3}^{-}$. 在没有动力分馏的条件 下, 硝化作用产生的硝酸盐中有 1 个氧原子源于水中的溶解氧, 另 2 个氧原子源于水体 ${ }^{[35]}$, 即 :

$$
\delta^{18} \mathrm{O}-\mathrm{NO}_{3}^{-}=2 / 3 \delta^{18} \mathrm{O}-\mathrm{H}_{2} \mathrm{O}+1 / 3 \delta^{18} \mathrm{O}-\mathrm{O}_{2}
$$

草海水体的 $\delta^{18} \mathrm{O}$-water 值在-13.4\% - 1.62\%o之间 (表 2), 大气中 $\delta^{18} \mathrm{O}-\mathrm{O}_{2}$ 理论值为 $23.5 \%$, 结合公式 (2) 计算得出的 $\delta^{18} \mathrm{O}-\mathrm{NO}_{3}^{-}$理论值为 $-1.10 \% 0 \sim 6.76 \%$. 由表 2 可知,草海湖水和井水的 $\delta^{18} \mathrm{O}-\mathrm{NO}_{3}^{-}$值基本均高 于理论值 (除 S1 和 S27), 而河水总体均在理论值范围内 (除 R6) ; 这表明河水出现了强烈的硝化作用, 而湖 水与井水则未发生硝化作用. 其中 S1 和 S27 因污染程度较高, 表现出一定的硝化作用; R6 是出水口, 因此与 湖水特征较为一致,未发生硝化作用.

在反硝化作用下, 微生物可将 $\mathrm{NO}_{3}^{-}$转化为 $\mathrm{N}_{2} \mathrm{O}$ 和 $\mathrm{N}_{2}$, 这一过程中轻同位素会被优先利用, 因此 $\delta^{15} \mathrm{~N}^{-} \mathrm{NO}_{3}^{-}$ 值和 $\delta^{18} \mathrm{O}-\mathrm{NO}_{3}^{-}$值在反硝化作用下随 $\mathrm{NO}_{3}^{-}$浓度降低而上升. 已有研究表明, 当水体中 $\delta^{15} \mathrm{~N} / \delta^{18} \mathrm{O}$ 比值在 $1.3 \sim$ 2.1 之间时, 表明有反硝化作用产生 ${ }^{[36-37]}$. 草海丰水期水体 $\delta^{15} \mathrm{~N} / \delta^{18} \mathrm{O}$ 比值均在这一范围之外, 加之水体 DO 浓度较高, 湖水和河水发生反硝化作用的可能性较小 ${ }^{[38-39]}$, 因此不考虑反硝化作用对同位素产生的分馏影 响, 将公式 (1) 中的分馏因子 $C_{j k}$ 设为 0 . 而部分井水点可能发生了一定程度的反硝化作用, 因此不对井水进 行基于 SIAR 模型的定量分析. 
2.4.3 主要硝酸盐来源贡献率分析 结合各来源氮氧同位素组成和 SIAR 模型, 进行定量分析可知, 在湖水 硝酸盐来源的贡献中 (图 7), 化肥和土壤有机 $N$ 对湖水硝酸盐来源的贡献率分别可达 $18 \% \pm 4 \%$ 和 $19 \% \pm$ $5 \%$. 牲畜粪便和城镇污水对湖水的贡献率分别为 $19 \% \pm 9 \%$ 和 $22 \% \pm 11 \%$. 大气降水的贡献率为 $22 \% \pm 12 \%$, 与其他来源贡献率相当, 表明大气降水同样是湖水硝酸盐的重要来源之一; 而草海湖水的氢氧同位素组成 特征也表明大气降水是草海湖水的重要来源. 总体上源于农业活动的化肥、土壤有机 $\mathrm{N}$ 和牲畜粪便贡献率 可达 $55 \%$. 河水硝酸盐来源的贡献城镇污水 $>$ 化肥 $\geqslant$ 土壤有机 $N>$ 牲畜粪便 $>$ 大气降水; 可见城镇污水 的大量排放和农业化肥的使用, 对草海周边河流的影响十分显著. 城镇污水来源贡献率达 $29 \% \pm 3 \%$, 化肥和 土壤有机 $N$ 贡献率分别为 $23 \% \pm 2 \%$ 和 $23 \% \pm 2 \%$, 牲畜粪便和大气降水则分别为 $21 \% \pm 2 \%$ 和 $4 \% \pm 1 \%$; 源于 农业活动的贡献率可达 $63 \% \sim 69 \%$. 根据井水 $\delta^{15} \mathrm{~N}^{-\mathrm{NO}_{3}^{-}}$和 $\delta^{18} \mathrm{O}-\mathrm{NO}_{3}^{-}$的分布关系可知 (图 6), 井水硝酸盐可 能主要来源于城镇污水和牲畜粪便以及土壤有机 $\mathrm{N}$ 的矿化; 同时井水点位于农业活动密集区, 在一定程度 上可能也受到化肥的影响.

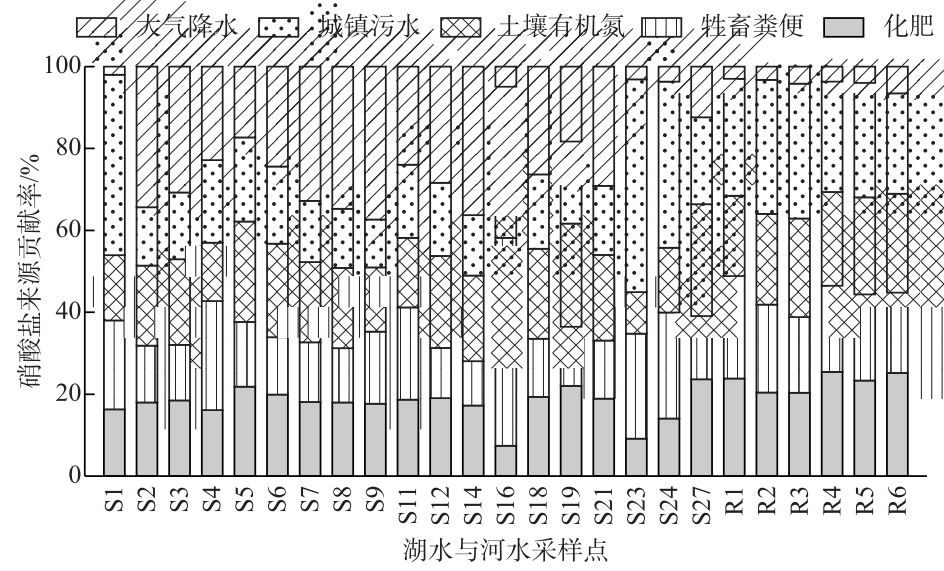

图 7 草海水体硝酸盐来源贡献率

Fig.7 Contribution rate of nitrate sources in Lake Caohai

\section{3 结论}

1) 草海水体水质参数表明草海各类水体水质特征差异较大; 草海水体阴离子浓度总体呈现出 $\mathrm{HCO}_{3}^{-}>$ $\mathrm{SO}_{4}^{2-}>\mathrm{Cl}^{-}>\mathrm{NO}_{3}^{-}$的变化规律; 水体表现出的高 $\mathrm{NO}_{3}^{-} / \mathrm{Cl}^{-}$值低 $\mathrm{Cl}^{-}$值的分布状况表明其主要受到农业活动的影 响,与大气降水关系不大.

2) 同位素结果分析表明草海湖水与河水丰水期硝酸盐主要源于农业生产活动,农业来源 (化肥、土壤有 机 $\mathrm{N}$ 和牲畜粪便 ) 贡献均高达 $50 \%$ 以上; 井水硝酸盐也可能受到农业活动的重要影响. 城镇污水和大气降 水对草海水体硝酸盐的贡献也不容小视, 其中城镇污水的贡献率可达 $20 \%$ 以上, 大气降水对湖水硝酸盐的 平均贡献达 $20 \%$ 左右.

3) 在草海的水污染防治和管控过程中, 需加强对农业活动的限制, 即在对草海周边区域进行退耕还林 的同时, 加强对周边地区畜牧业和养殖业的管理. 并完善城镇污水管网建设和污水处理设备的升级改造, 对 城镇污水进行管网收集和集中处理，从而减少由农业活动和城镇化发展对草海生态环境的破坏.

\section{4 参考文献}

[ 1 ] Jin Z, Zheng Q, Zhu C et al. Contribution of nitrate sources in surface water in multiple land use areas by combining isotopes and a Bayesian isotope mixing model. Applied Geochemistry, 2018, 93: 10-19.

[ 2 ] Matiatos, Ioannis. Nitrate source identification in groundwater of multiple land-use areas by combining isotopes and multivariate statistical analysis: A case study of Asopos basin (Central Greece). Science of the Total Environment, 2016, 541: 
802-814.

[ 3 ] Liu Y, Wang Z, Guo H et al. Modelling the effect of weather conditions on cyanobacterial bloom outbreaks in Lake Dianchi: A Rough Decision-Adjusted Logistic Regression Model. Environmental Modeling \& Assessment, 2013, 18 (2) : 199-207.

[ 4 ] Gruber N, Galloway JN. An earth-system perspective of the global nitrogen cycle. Nature, 2008, 451(7176) : 293-296.

[ 5 ] Zhang Y, Li F, Zhang Q et al. Tracing nitrate pollution sources and transformation in surface- and ground-waters using environmental isotopes. Science of the Total Environment, 2014, 490: 213-222.

[ 6 ] Bu H, Zhang Y, Meng W et al. Effects of land-use patterns on in-stream nitrogen in a highly-polluted river basin in Northeast China. Science of the Total Environment, 2016, 553: 232-242.

[ 7 ] Weng TN, Liu CW, Kao YH et al. Isotopic evidence of nitrogen sources and nitrogen transformation in arsenic-contaminated groundwater. Science of the Total Environment, 2016, 578: 167-185.

[ 8 ] Archana A, Li L, Shuh-Ji K et al. Variations in nitrate isotope composition of wastewater effluents by treatment type in Hong Kong. Marine Pollution Bulletin, 2016, 111(1/2): 143-152.

[ 9 ] Jin Z, Qin X, Chen L et al. Using dual isotopes to evaluate sources and transformations of nitrate in the West Lake watershed, eastern China. Journal of Contaminant Hydrology, 2015, 177/178: 64-75.

[10] Mayer B, Wassenaar LI. Isotopic characterization of nitrate sources and transformations in Lake Winnipeg and its contributing rivers, Manitoba, Canada. Journal of Great Lakes Research, 2012, 38( supp-S3) : 135-146.

[11] Li R, Ruan X, Bai Y et al. Effect of wheat-maize straw return on the fate of nitrate in groundwater in the Huaihe River Basin, China. Science of the Total Environment, 2017, 592: 78-85.

[12] Li SL, Liu CQ, Li J et al. Assessment of the sources of nitrate in the Changjiang River, China using a nitrogen and oxygen isotopic approach. Environmental Science \& Technology, 2010, 44(5) : 1573-1578.

[13] Yue FJ, Li SL, Liu CQ et al. Tracing nitrate sources with dual isotopes and long term monitoring of nitrogen species in the Yellow River, China. Scientific Reports, 2017, 7(1): 8537.

[14] Elisante E, Muzuka ANN. Assessment of sources and transformation of nitrate in groundwater on the slopes of Mount Meru, Tanzania. Environmental Earth Sciences, 2016, 75(3): 1-15.

[15] Musgrove M, Opsahl SP, Mahler BJ et al. Source, variability, and transformation of nitrate in a regional karst aquifer: Edwards aquifer, central Texas. Science of the Total Environment, 2016, 568: 457-469.

[16] Soto DX, Koehler G, Wassenaar LI et al. Spatio-temporal variation of nitrate sources to Lake Winnipeg using N and O isotope $\left(\delta^{15} \mathrm{~N}, \delta^{18} \mathrm{O}\right)$ analyses. Science of the Total Environment, 2019, 647: 486-493.

[17] Liu S, Wu F, Feng W et al. Using dual isotopes and a Bayesian isotope mixing model to evaluate sources of nitrate of Tai Lake, China. Environmental Science and Pollution Research, 2018, 25(32) : 32631-32639.

[18] Wang M, Lu B, Wang $\mathrm{J}$ et al. Using dual isotopes and a bayesian isotope mixing model to evaluate nitrate sources of surface water in a drinking water source watershed, East China. Water, 2016, 8(8) : 355.

[19] Zhang JL, Wu H, Yu LF et al. Structure feature of typical Karst forest plant community in Caohai wetland watershed of Guizhou Province. Journal of Southern Agriculture, 2013, 44(3): 471-477. [张建利, 吴华, 喻理飞等. 贵州草海湿地 流域典型喀斯特森林植物群落结构特征. 南方农业学报, 2013, 44(3)：471-477.]

[20] Xia PH, Xue F, Kong XL et al. Spatial characteristics and impact of water quality in agricultural dicth systems of Caohai wetland in the Guizhou plateau, China. Environmental Chemistry, 2012, 31(8): 1201-1207. [夏品华, 薛飞, 孔祥亮 等. 贵州草海湿地农田渠系水质空间分异特征及影响分析. 环境化学, 2012, 31(8): 1201-1207.]

[21] Yang HQ, Chen JA, Liu W et al. Distribution characteristics and controlling factors of total organic carbon, total nitrogen, and total phosphorus in sediments of Caohai Lake, China. Earth and Environment, 2016, 44(3): 297-303. [杨海全, 陈 敬安, 刘文等. 草海沉积物营养元素分布特征与控制因素. 地球与环境, 2016, 44(3): 297-303.]

[22] Zhang HH, Li MJ, Yao SL eds. Analysis of Lake Caohai. Guiyang: Guizhou Science and Technology Press, 2005: 228267. [张华海, 李明晶, 姚松林. 草海研究. 贵阳: 贵州科技出版社, 2005: 228-267.]

[23] Xu T, Xu Y, Jiang B et al. Evaluation of the ecosystem services in Caohai Wetland, Guizhou Province. Acta Ecologica Sinica, 2015, 35(13) : 4295-4303. [徐婷, 徐跃, 江波等. 贵州草海湿地生态系统服务价值评估. 生态学报, 2015, $35(13): 4295-4303$.

[24] Zhu ZJ, Chen JA, Zeng Y. Paleotemperature variations at Lake Caohai, southwestern China, during the past 500 years: 
Evidence from combined $\delta^{18} \mathrm{O}$ analysis of $\delta$ cellulose and carbonates. Science China: Earth Sciences, 2014, 44(2) : 250258. [ 朱正杰, 陈敬安, 曾艳. 草海地区过去 500 年来古温度重建: 来自沉积物纤维素结合碳酸盐氧同位素的证 据. 中国科学: 地球科学, 2014, 44(2): 250-258.]

[25] Zhang ZL, Tan H, He JL et al. Distribution characteristics and source identification of heavy metals in surface sediments of Caohai Lake in Guizhou. Ecology and Environmental Sciences, 2018, 27(12): 2314-2320. [张转玲, 谭红, 何锦林等. 贵州草海表层沉积物重金属污染特征及来源分析. 生态环境学报, 2018, 27(12): 2314-2320.]

[26] Parnell AC, Inger R, Bearhop S et al. Source partitioning using stable isotopes: Coping with too much variation. PLoS ONE, 2010, 5(3) : e9672.

[27] Li SL, Liu CQ, Li J et al. Assessment of the sources of nitrate in the changjiang river, china using a nitrogen and oxygen isotopic approach. Environmental Science \& Technology, 2010, 44(5) : 1573-1578.

[28] Liu CQ, Li SL, Lang YC et al. Using delta ${ }^{15} \mathrm{~N}$ - and delta ${ }^{18} \mathrm{O}$-values to identify nitrate sources in karst ground water, Guiyang, southwest China. Environmental Science \& Technology, 2006, 40(22) : 6928.

[29] Widory D, Petelet-Giraud E, Négrel P et al. Tracking the sources of nitrate in groundwater using coupled nitrogen and boron isotopes: A synthesis. Environmental Science \& Technology, 2005, 39(2) : 539-548.

[30] Zhu SD, Zhang F, Zhang HW et al. Seasonal variation of the isotope and hydrochemical characteristics of the main lake rivers in Lake Ebinur. J Lake Sci, 2018, 30(6) : 1707-1721. DOI: 10.18307/2018.0622. [ 朱世丹, 张飞, 张海威等. 新疆艾比湖主要人湖河流同位素及水化学特征的季节变化. 湖泊科学, 2018, 30(6): 1707-1721.]

[31] Liu JR, Song XF, Yuan GF et al. Characteristics of $\delta^{18} \mathrm{O}$ in precipitation over Eastern Monsoon China and the water vapor sources. Chinese Sci Bull, 2009, (22) : 3521-3531. [柳鉴容, 宋献方, 袁国富等. 中国东部季风区大气降水 $\delta^{18} \mathrm{O}$ 的 特征及水汽来源. 科学通报, 2009, (22) : 3521-3531.]

[32] Huang YM, Zhang XP, Sun X et al. Seasonal variations of stable isotope in precipitation and atmospheric water vapor and their relationship with moisture transportation in Changsha City. Scientia Geographica Sinica, 2015, 35(4) : 498-506. [黄 一民, 章新平, 孙搌等. 长沙大气水汽、降水中稳定同位素季节变化及与水汽输送关系. 地理科学, 2015, 35(4): 498-506.]

[33] Li G, Zhang XP, Xu YP et al. Characteristics of stable isotopes in precipitation and their moisture sources in mengzi region, southern Yunnan. Environmental Science, 2016, 37(4): 1313-1320. [李广, 章新平, 许有鹏等. 滇南蒙自地区降 水稳定同位素特征及其水汽来源. 环境科学, 2016, 37(4) : 1313-1320.]

[34] Kendall C, McDonnell JJ. Isotope tracers in catchment hydrology. Amsterdam: Elseiver Science, 1998: 519-576.

[35] Xing M, Liu W. Using dual isotopes to identify sources and transformations of nitrogen in water catchments with different land uses, Loess Plateau of China. Environmental Science \& Pollution Research, 2016, 23(1) : 388-401.

[36] Xue D, Botte J, De BB et al. Present limitations and future prospects of stable isotope methods for nitrate source identification in surface and groundwater. Water Research, 2009, 43(5) : 1159-1170.

[37] Yue FJ, Liu CQ, Li SL et al. Analysis of $\delta^{15} \mathrm{~N}$ and $\delta^{18} \mathrm{O}$ to identify nitrate sources and transformations in Songhua River, Northeast China. Journal of Hydrology, 2014, 519: 329-339.

[38 ] PiñA-Ochoa E, Álvarez-Cobelas M. Denitrification in aquatic environments: A cross-system analysis. Biogeochemistry (Dordrecht), 2006, 81(1): 111-130.

[39] Xue D, Baets BD, Cleemput OV et al. Use of a Bayesian isotope mixing model to estimate proportional contributions of multiple nitrate sources in surface water. Environmental Pollution, 2012, 161 : 43-49. 